EDITORIAL

\title{
Lower Rate of Blood Transfusion after Heart Surgery in a Tertiary Hospital
}

\author{
Leonardo Secchin Canale ${ }^{\circledR}$ \\ Instituto Nacional de Cardiologia, Rio de Janeiro, RJ - Brazil \\ Editorial referring to the article: Transfusion of Blood Products in the Postoperative of Cardiac Surgery
}

Special interest in surgical bleeding and methods to limit its occurrence is growing after the possibility that transfusion of blood products might be causally related to complications and negative outcomes has been raised. ${ }^{1}$ In the same vein, studies have been conducted to evaluate whether limiting blood product transfusions (ie, being more conservative in the indication for it) would increase the safety of transfusion or even reduce some patterns of complications. ${ }^{2}$ The current study is a contribution to this larger discussion.

Moraes et al. ${ }^{3}$ report the experience of a large tertiary center in bleeding patterns after heart operations. Four hundred and twenty-three patients $(51 \%$ coronary artery bypass surgery and 33\% valve operations) were evaluated for total bleeding and for the use of blood products. Perioperative bleeding was measured by weighing sponges, a validated method for a difficult enterprise. Postoperative bleeding was determined by the total chest tube output in the first $24 \mathrm{~h}$ after the end of the operation.

Interestingly, the median bleeding volume during surgery $(413 \mathrm{~mL})$ and after surgery $(200 \mathrm{~mL})$ were higher than the mean total bleeding volume (353 mL), showing that probably some outlier heavy bleeders skewed the curve to the right. Figure 1 clearly shows us that, although most patients presented with low and controlled total bleeding, a relatively small proportion of the patients suffered severe bleeding with consequential much higher transfusion amounts. The authors indeed show that a weak correlation was found between total bleeding volume and need for transfusion. One should be attentive that single

\section{Keywords}

Thoracic Surgery; Coronary Artery Bypass; Blood transfusion.

Mailing Address: Leonardo Secchin Canale

Rua das Laranjeiras, 374. Postal Code: 22240-006, Rio de Janeiro, RJ - Brazil. E-mail: leonardo.canale@gmail.com

DOI: https://doi.org/10.36660/ijcs.20210157 bleeding events can be catastrophic and put pressure on the blood bank system.

Only $40 \%$ of patients required any blood product transfusion, a rate lower than that of previous reports. Another interesting aspect of this retrospective cohort is that the majority of blood products being transfused was red blood cell packs. There was indeed a very small number of patients who needed either fresh frozen plasma or platelets (only 26 patients). A possible explanation for both facts could be that total cardiopulmonary bypass time was, on average, short. The operations were probably performed as emergencies. The authors should, however, better describe whether some known specific strategies for blood salvage were present during the operations, such as the use of cell savers or preoperative erythropoietin.

Regarding the complications experienced by the cohort of patients, it is not possible, with this study design, to draw causal correlations between the amount of blood transfusion and the complication rate. It is a real challenge to differentiate previous risk factors that have led both to bleeding and to complications from possible unwanted effects of the transfusions themselves. This line of research reveals itself as a complex endeavor with conflicting results among different studies. In a large British multicenter randomized trial ${ }^{2}$ comparing a restrictive threshold for transfusion (postoperative hemoglobin $<7.5 \mathrm{~g} /$ $\mathrm{dL}$ ) against a liberal one (postoperative hemoglobin $<9.0 \mathrm{~g} / \mathrm{dL}$ ), the conclusions were dubious in terms of complications, quality of life issues, and even costs. Although the restrictive approach was noninferior to the liberal one, the authors themselves reported that "secondary findings create uncertainty about recommending restrictive transfusion," as well as a trend toward higher mortality. A Canadian multicenter randomized trial ${ }^{4}$ focusing on patients at moderate-tohigh risk for death, on the other hand, demonstrated the safety of a restrictive approach up to 6 months after surgery, with no increase in any complication.

The authors should be congratulated on their enterprise in adequately quantifying the amount of 
bleeding and transfusion requirement in their surgical cohort. Such initiatives might reveal what to expect in terms of blood resource utilization in a tertiary center.
Further studies should be performed to test particular interventions to diminish transfusion requirements and their impact on clinical complications.

\section{References}

1. Koch CG, Li L, Duncan AI, Mihaljevic T, Cosgrove DM, Loop FD, et al. Morbidity and Mortality Risk Associated With Red Blood Cell and Bloodcomponent Transfusion in Isolated Coronary Artery Bypass Grafting. Crit Care Med. 2006;34(6):1608-16. doi: 10.1097/01.CCM.0000217920.48559.D8.

2. Reeves BC, Pike K, Rogers CA, Brierley RC, Stokes EA, Wordsworth $\mathrm{S}$, et al. A Multicentre Randomised Controlled Trial of Transfusion Indication Threshold Reduction on Transfusion Rates, Morbidity and Health-care Resource use Following Cardiac Surgery (TITRe2). Health Technol Assess. 2016;20(60):1-260. doi: 10.3310/hta20600.

3. Moraes A, Giordani JN, Borges CT, Mariani PE, Costa LM, Bridi LH, et al Transfusion of Blood Products in the Postoperative of Cardiac Surgery. Int J Cardiovasc Sci. 2021; 34(5):499-505. doi: 10.36660/ijcs.20190192.

4. Mazer CD, Whitlock RP, Fergusson DA, Belley-Cote E, Connolly K, Khanykin B, et al. Six-Month Outcomes after Restrictive or Liberal Transfusion for Cardiac Surgery. N Engl J Med. 2018;379(13):1224-33. doi: 10.1056/NEJMoa1808561. 